\title{
CONVERGED RADIO OVER FIBER AND OFDM-PON BASED ON SINGLE- SIDEBAND FREQUENCY TRANSLATION TECHNIQUE
}

\author{
Taha H. Dahawi ${ }^{1}$, Zulfadzli Yusoff ${ }^{1 *}$, Redhwan Q. Shaddad ${ }^{2}$, Mohd Shahril Salleh $^{3}$, \\ John M. Senior ${ }^{4}$
}

${ }^{1}$ Faculty of Engineering, Multimedia University, Persiaran Multimedia, 63100 Cyberjaya, Selangor, Malaysia

${ }^{2}$ Faculty of Engineering, Taiz University, Taiz, Yemen

${ }^{3}$ TM R\&D, Lingkaran Teknokrat Timur, Cyberjaya 63000, Malaysia

${ }^{4}$ Optical Networks Group, University of Hertfordshire, Hatfield AL10 9AB, UK

(Received: November 2018 / Revised: December 2018 / Accepted: November 2019)

\begin{abstract}
Future passive optical networks will require simultaneous provision of wired and wireless services to provide high-capacity and high-speed information access network to overcome the capacity demand. In this paper, a converged fiber-wireless (FiWi) network architecture including an orthogonal frequency division multiplexing passive optical network (OFDM-PON) and a radio over fiber (RoF) system is proposed. Two multiple-input multiple-output radio over fiber channels are inserted into the left and right side of OFDM-PON spectrum, using a single-sideband frequency translation (SSB-FT) technique. The significant merit of the proposed architecture is its high spectral efficiency as the two multiple-input multiple-output radio over fiber channels and OFDM-PON transmit at the same frequency, which reduces the complexity of transceiver design by applying a novel method for the implementation of local oscillators in both transmitter and receiver. A proof-of-concept downstream link over $20 \mathrm{~km}$ standard-PON was conducted by simulation to demonstrate the performance of the proposed converged fiber-wireless network architecture and the link performance was assessed using error vector magnitude and bit error rate.
\end{abstract}

Keywords: FiWi Network; OFDM-PON; RoF; SSB-FT

\section{INTRODUCTION}

Mobile data traffic is increasing exponentially due to the rapid advancement in smartphone technology. The estimation of the total video communication traffic over mobile and fixed systems by 2020 will be around 2,600 times the traffic in 2010 (Osseiran, 2014; Suryanegara, 2016; Tornatore et al., 2017). Therefore, the next generation mobile net work would require high-capacity and high-speed information access networks to overcome the capacity demand (Mitchell, 2014; Kani et al., 2017; Suryanegara \& Asvial, 2018).

The parallel demand for both capacity and mobility requires researchers to come up with solutions that fuse the two aspects based on optical access network (Jarrar et al., 2015). The integration of such wireless system with optical access network is called a fiber-wireless (FiWi) network (Liu \& Effenberger, 2017; Tzanakaki et al., 2017).

${ }^{*}$ Corresponding author's email: zulfadzli.yusoff@mmu.edu.my, Tel. +603-8312 5747

Permalink/DOI: https://doi.org/10.14716/ijtech.v10i7.3265 
Radio over fiber (RoF) is one of the technologies that could be used in FiWi network to integrate the wireless system with optical network (Jia et al., 2007; Lim et al., 2018). It allocates and controls multiple wireless services at the central station to deliver the wireless signals as analogue signals to the base stations (BSs) through the optical fiber infrastructure. Thus, it greatly reduces the BS complexity and cost (Latunde, 2016). In addition, to reduce the capital expenditure (CAPEX) of RoF installation, RoF system should be integrated with the currently deployed optical network access using passive optical network (PON) which has ready fiber infrastructure in the form of fiber to the home (FTTH) and to the curb (FTTC) (Mitchell, 2014; Gutiérrez et al., 2016).

Passive optical networks are widely deployed today within optical access networks, which provide users with high-capacity and high-speed data at affordable cost (Da Silva et al., 2017). PONs based on orthogonal frequency division multiplexing (OFDM-PON) utilize the privileges of OFDM transmission, such as chromatic dispersion tolerance, long haul transmission, smooth convergence with current wireless system as well as high-capacity delivery (Cano et al., 2015; Senior et al., 2012). These advantages makes OFDM-PON one of the candidates for future access network implementation. The network topology for OFDM-PON comprises one optical line terminal (OLT) located at the central station and several optical network units (ONUs) at the customer side. In the optical distribution network (ODN), a passive optical power splitter is used to connect all the ONUs to the OLT. Figure 1 represents the topology of the standard OFDM-PON, showing that in the downstream (DS) scenario, signals are generated and optically modulated in the OLT and then transmitted through $20 \mathrm{~km}$ of a standard single mode fiber (SSMF). The signals are split to the ONUs via a splitter and then demodulated in ONUs at customer side. However, for the upstream (US) scenario, signals are transmitted from the ONUs to the OLT either using the same wavelength as that of the DS or a different wavelength. The ONU could be a house, a business office, or a base station for the wireless end, which could be utilized through the RoF technology.

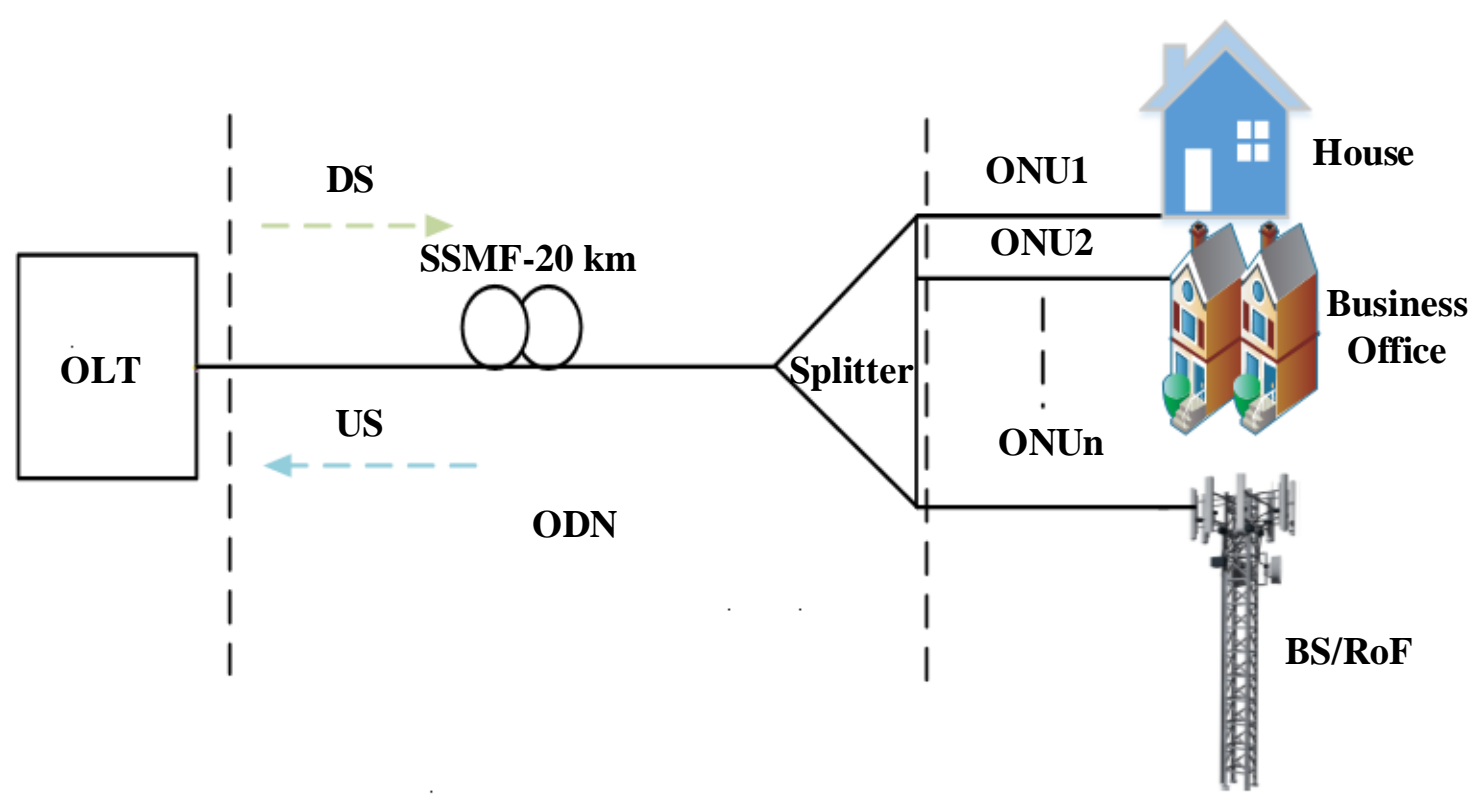

Figure 1 OFDM-PON architecture

RoF in PONs has drawn considerable interest in recent research due to its simplicity and low cost deployment (Zhu et al., 2013; Wagner et al., 2016;). The advantage of these architectures is their capacity for scalability. However, some of the active components such as wavelength division multiplexer and demultiplexer are required to be used in the ODN section and a narrow optical filter is needed at the ONU resulting in expensive network architecture. Moreover, the 
coexistence of multi-RoF and time and wavelength division multiplexing passive optic network (TWDM-PON) has been recently reported in (Oliveira et al., 2017), where RoF and TWDMPON are two separate systems each with different wavelengths, causing the TWDM-PON to have impact on the RoF system due to the nonlinear effects of cross-phase modulation.

To overcome the problems mentioned above, this paper proposes a FiWi coexistence network between RoF and OFDM-PON, wherein both systems transmit with a single wavelength. In addition, expensive optical components such as tuneable optical filters at the ONUs and a WDM demultiplexer at the ODN are eliminated. At the earlier development stage of OFDM-PON led by the ACCORDANCE project (Kanonakis et al., 2012), RoF had been integrated with OFDMPON through coexistence of multiple WiMAX and LTE channels over the PON and was successfully transmitted through a single channel. However, each channel required a local oscillator (LO) and bandpass filter (BPF) at the transmitter and receiver part of the PON system. This leads to a complex system, especially if multiple-input multiple-output (MIMO) system is considered. Therefore, a different technique is required to eliminate some LOs for the existing network to be efficiently used.

In this research, the coexistence of the two MIMO-RoF channels and OFDM-PON has been designed such that both systems transmit with a single optical channel and same carrier frequency utilizing the single-sideband frequency translation (SSB-FT) technique. The use of this technique was reported in (Liu \& Seeds, 2010) for MIMO-RoF systems in order to reduce the number of LOs for three MIMO channels from three LOs to only one. However, the authors considered only wireless services and did not utilize the PON fiber infrastructure for the RoF system. In Elmagzoub et al. (2016), the authors reported a network architecture that could transmit two MIMO-RoF and wired signal over a standard PON system using polarization multiplexing. However, this method is only applicable for wavelength division multiplexing passive optical network (WDM-PON) and also requires two dual-drive Mach-Zehnder Modulator (DD-MZM) and polarization controllers for modulating the two MIMO signals and another MZM for the baseband wired signal, which make the system complex and costly. Thus, the contribution of this paper is to utilize SSB-FT in our proposed converged FiWi architecture including two MIMO-RoF and wired OFDM-PON to provide a cost-efficient transceiver design by reducing the number of LOs implementation that are required to allocate each MIMO and wired signal in the aggregated OFDM spectrum so that they do not overlap in the frequency domain. As a result, they could be modulating with only one MZM optical modulator and transmitting over a single optical channel without the need for a WDM demultiplexer at the ODN part of the PON system.

This paper is organized as follows: In Section 2, the description of the proposed method is presented; Section 3 illustrates the simulated modeling of the proposed network. Section 4 discusses the results and performance. Finally, concluding remarks are made in Section 5.

\section{DESCRIPTION OF THE PROPOSED METHOD}

As highlighted in Section I, the single-sideband frequency translation (SSB-FT) technique was proposed previously in (Liu \& Seeds, 2010) for three MIMO-RoF channels to be transmitted on a single wavelength and single carrier frequency without the need to use a WDM system. In this case, one MIMO-channel was considered as the central band and the other two MIMO channels were located as left and right side bands with same carrier frequency. Hence this technique was referred to as single-sideband frequency translation. This approach was utilized in our coexistence FiWi network to have both wired signal and two MIMO-RoF channels over a standard OFDM-PON to reduce the cost and to improve spectral efficiency. 
Figure 2 describes the utilization of SSB-FT technique in our proposed network architecture at the transmission end, where the two MIMO-RoF channels are inserted at the left and right side of wired signal that represents the OFDM-PON. Both the RoF channels and the wired OFDMPON have the same carrier frequency, $f_{c}$, of $2.5 \mathrm{GHz}$. By applying the SSB-FT technique, the two MIMO-RoF channels are mixed with $1 \mathrm{GHz} \mathrm{LO}$, which shifts each channel with lower and upper bands to $1.5 \mathrm{GHz}$ and $3.5 \mathrm{GHz}$ respectively. A BPF with center frequency $f_{c}=3.5 \mathrm{GHz}$ selects the upper band of MIMO1 and another BPF with $f_{c}=1.5 \mathrm{GHz}$ is used to filter the lower band of MIMO2. Then, the two MIMO channels are associated with the wired signal that will be transported through the optical channel to different ONUs.

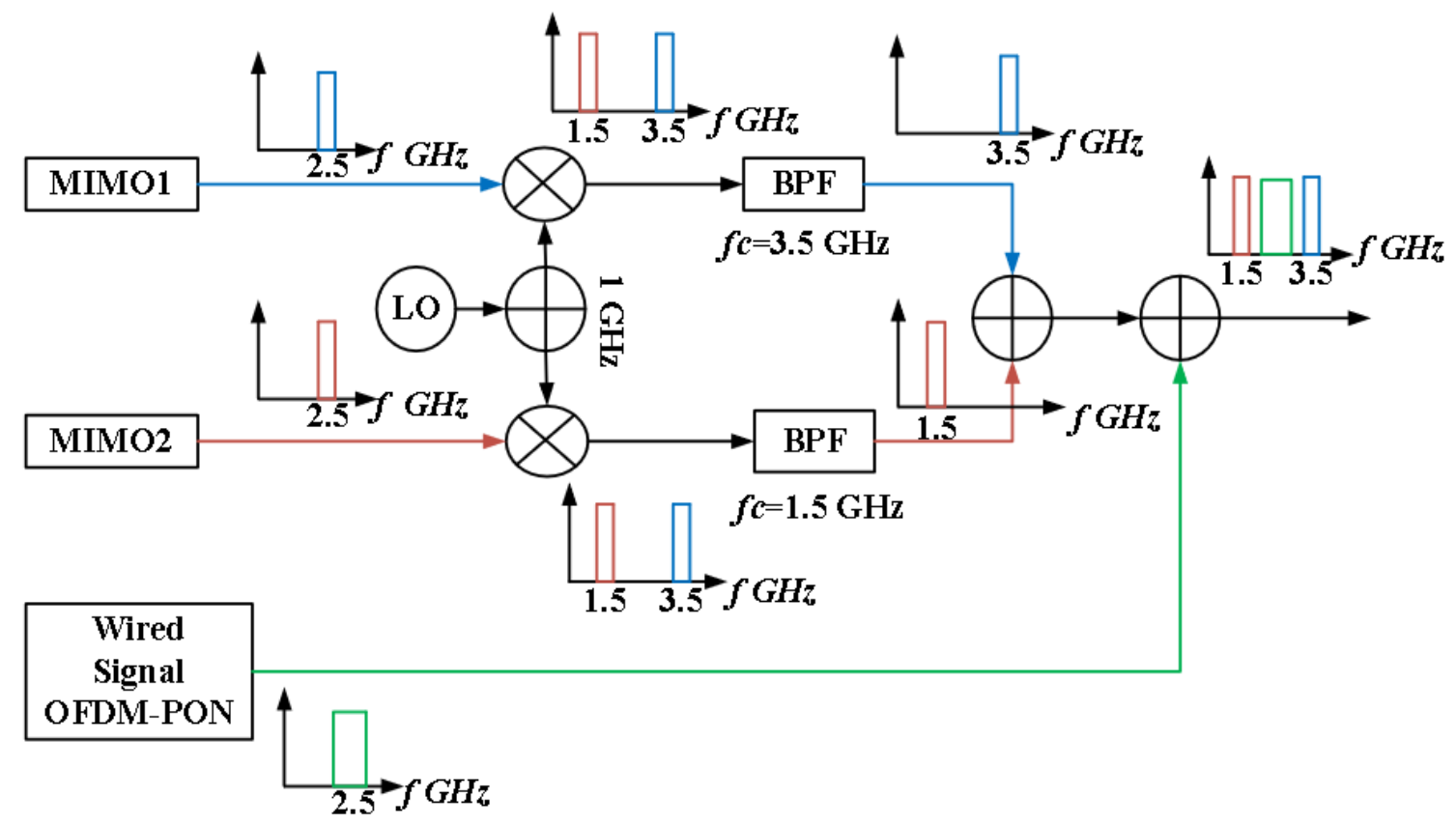

Figure 2 Implementation of SSB-FT technique over the proposed architecture

\section{SYSTEM DESCRIPTION AND MODELING}

The network architecture is modeled using the commercially available VPI Transmission Maker as shown in Figure 3. The OFDM-PON was designed based on the ACCORDANCE network architecture (Kanonakis et al., 2012), wherein the OFDM signal is upconverted to 2.5 $\mathrm{GHz}$ and transmitted using intensity modulation-direct detection (IM/DD) method. Both OFDM-PON and MIMO-RoF signals are implemented based on 16 QAM modulation. The capacity for the OFDM-PON is 2.5 Gbps while both MIMO-RoF signals have $40 \mathrm{Mbps}$ data rate. The design parameters of the proposed network architecture is described in Table 1.

At the OLT, the two MIMO-RoF and wired signals are generated using VPI, and they are electrically combined utilizing SSB-FT as described in Section 2, where all signals are upconverted to the same frequency of $2.5 \mathrm{GHz}$. By adapting the SSB-FT, each MIMO-RoF signal is mixed with $1 \mathrm{GHz} \mathrm{LO}$, which produces an upper sideband at $3.5 \mathrm{GHz}$ and a lower side band at $1.5 \mathrm{GHz}$ and other higher order sidebands with different frequencies. A bandpass filter with center frequency $\mathrm{fc}=3.5 \mathrm{GHz}$ is used to select the upper sideband for MIMO1. Another bandpass filter with $\mathrm{fc}=1.5 \mathrm{GHz}$ can be used to select the lower sideband for MIMO2. After the mixing process, the original frequency of $2.5 \mathrm{GHz}$ is left unoccupied so that the wired OFDM-PON signal can be inserted as indicated in Figure 4a. 
Table 1 Design parameters

\begin{tabular}{lc}
\hline \multicolumn{1}{c}{ Parameter } & Value \\
\hline Data rate for OFDM-PON & $2.5 \mathrm{Gbps}$ \\
Data rate for each MIMO-RoF signal & $40 \mathrm{Mbps}$ \\
Carrier frequency & $2.5 \mathrm{GHz}$ \\
Modulation & $16 \mathrm{QAM}$ \\
LO & \\
Frequency & $1 \mathrm{GHz}$ \\
Laser & \\
Power & $10 \mathrm{dBm}$ \\
Linewidth & $100 \mathrm{KHz}$ \\
MZM & \\
Extinction ratio & $30 \mathrm{~dB}$ \\
SSMF & \\
Length & $20 \mathrm{~km}$ \\
Attenuation & $0.2 \mathrm{~dB} / \mathrm{km}$ \\
Dispersion coefficient & $17 \mathrm{e}^{-6} \mathrm{~s} / \mathrm{m}^{2}$ \\
Variable Optical Attenuator (VOA) & \\
Attenuation & $12.4 \mathrm{~dB}$ \\
Splitter & \\
Splitting ratio & $1: 16$ \\
Photodetector (PD) & \\
Responsivity & $1 \mathrm{~A} / \mathrm{W}$ \\
Type & $\mathrm{PIN}$ \\
\hline
\end{tabular}

The combined signal is fed to the power control unit and then the Mach-Zehnder Modulator (MZM) RF input biased at its quadrature point. The RF drive power into the MZM is optimized through the power control unit as shown in Figure 3 in order to avoid the non-linearity issue that produces intermodulation distortion, which leads to the degradation of the overall performance. The optimum RF drive power that was chosen in the proposed network is $-2 \mathrm{dBm}$. Details on optimization of the RF drive power was reported in our previous publication (Dahawi et al., 2018). A continuous wave laser with $193.1 \mathrm{THz}$ frequency is fed into the second arm of the MZM to modulate the combined signal. The output optical spectrum after the MZM is shown in Figure $4 \mathrm{~b}$, which consists of optical double-sideband (ODSB) modulation. Since the standard length for PON is around $20 \mathrm{~km}$, the chromatic dispersion does not have significant effect on the performance as discussed in Lin et al. (2012). Because of this, ODSB was chosen in the proposed architecture to avoid utilizing a narrow optical filter after MZM which adds cost to the network. At the ODN, the combined signal is transmitted over an SSMF with wavelength equivalent to $193.1 \mathrm{THz}$ in frequency. A power splitter with 1:16 splitting ratio was utilized through the VOA with $12.4 \mathrm{~dB}$ insertion loss to split the transmitted optical signal to the different ONUs.

At the ONU/wired signal, BPF is applied after photodetector conversion to select the wired signal centered at $2.5 \mathrm{GHz}$ as shown in Figures $4 \mathrm{c}$ and $4 \mathrm{~d}$. However, at the ONU/RoF, a bandstop filter with $\mathrm{fc}=2.5 \mathrm{GHz}$ and bandwidth $=2 \mathrm{GHz}$ is utilized first to block the wired signal and then left only with RoF bands as shown in Figure 4e. Then, the signal after bandstop filter is divided into two parts for the reverse SSB-FT process, where the same BPFs and LO design parameters as in the OLT are used at the ONUs. The spectrum of the reverse process is shown in Figures $4 \mathrm{f}$ and $4 \mathrm{~g}$. It is important to note that only one LO is applied at the receiver resulting in a simple receiver design. In this paper, to verify the performance of our proposed RoF link, the two MIMO-RoF systems are directly demodulated without wireless transmission. After demodulation process, the quality of each signal is measured through error vector magnitude $(\mathrm{EVM})$ and bit error rate (BER). 


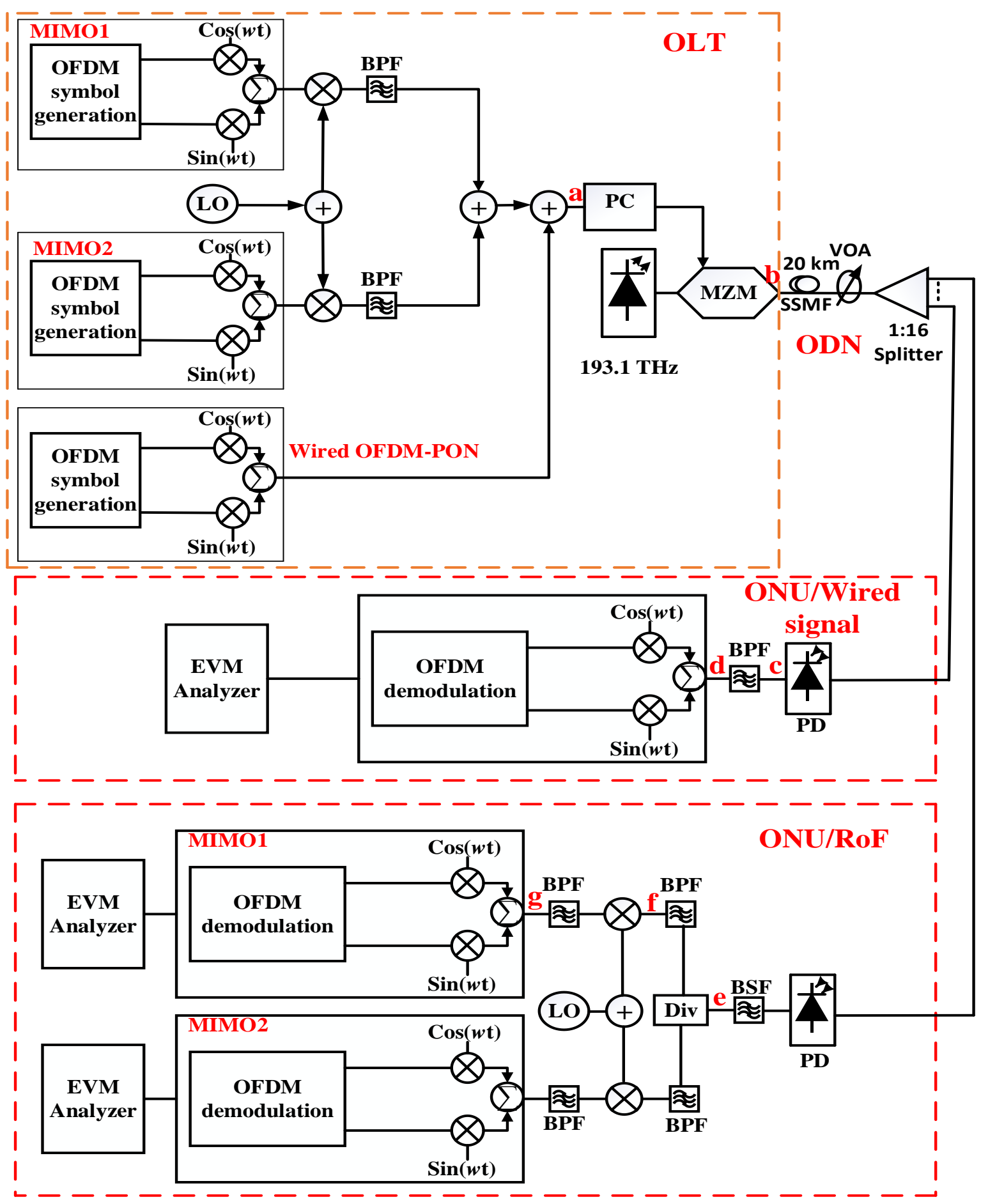

Figure 3 Simulated setup of converged OFDM-PON and RoF system 

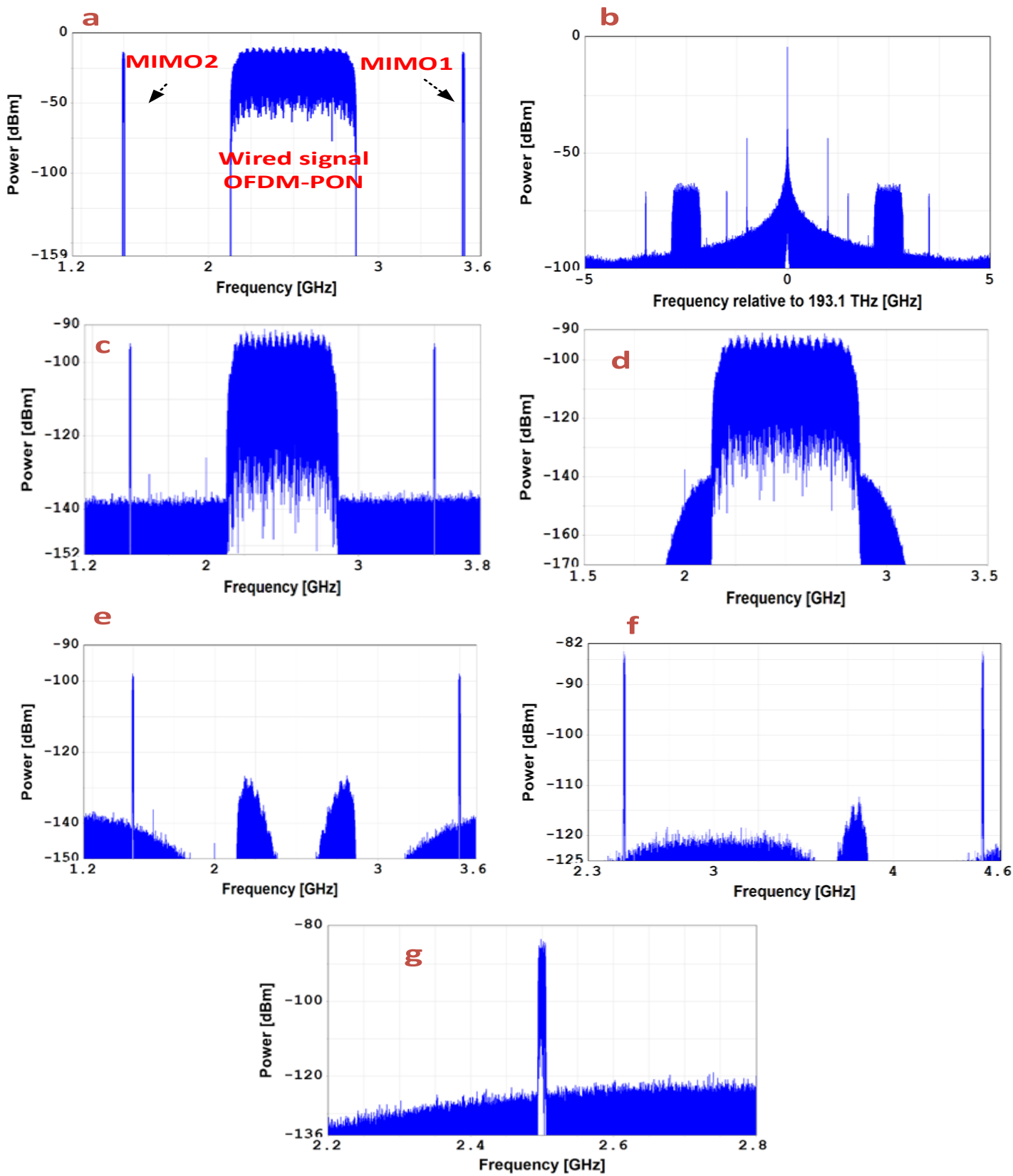

Figure 4 The spectra of different optical and electrical signals at assigned points of Figure 3

\section{SIMULATED PERFORMANCE AND DISCUSSION}

In order to check the feasibility of the proposed architecture, the downlink transmission performance for both wired OFDM-PON and MIMO-RoF signals was tested and evaluated based on EVM and BER with and without (back-to-back) (B-T-B) transmission over $20 \mathrm{~km}$ of fiber.

Figure 5 shows EVM versus received optical power relating to two MIMO-RoF and wired OFDM-PON signals, showing the performance in B-T-B cases and over $20 \mathrm{~km}$ of fiber. The received optical power was measured after the fiber and before the photodetector by changing the value of the VOA as shown in Figure 3. The results are shown for received optical power below $-9 \mathrm{dBm}$ where EVM could be reliably calculated. In all cases for MIMO1, MIMO2, and wired signal, there is no penalty due to fiber transmission, indicating the ability of RoF system and wired OFDM-PON signal to deal with chromatic dispersion that could affect the performance. At the EVM of 5\%, the required minimum received optical power are $-11.5 \mathrm{dBm}$ 
and $-12.8 \mathrm{dBm}$ for MIMO1 and MIMO2, respectively. There is a power penalty of $1.3 \mathrm{~dB}$ due to the finite input-output isolation of the doubled-balanced microwave mixers of the singlesideband frequency translation process, which led to the residual level at the original carrier frequency of $2.5 \mathrm{GHz}$ (Liu \& Seeds, 2010). For the wired OFDM-PON signal, at the EVM of $15 \%$, the receiver sensitivity is around $-10.5 \mathrm{dBm}$. It can be noticed that the required minimum received optical power for our proposed system that could be an overlap between the EVM threshold of both MIMO-RoF and wired OFDM-PON is $-10.5 \mathrm{dBm}$. The EVM threshold for RoF channels is lower than wired OFDM-PON so that satisfactory performance is attained for the wireless signals, taking into account additional wireless channel (IEEE Std, 2006), which could be required after photodetection that are not addressed in this paper. Figure 6 shows the received constellation points after $20 \mathrm{~km}$ fiber transmission of the MIMO1, MIMO2, and wired signal at received optical power equivalent to $-9 \mathrm{dBm}$. The figure indicates good performance in terms of the constellation points where there are no more points received in error leading to EVM values of $3.4 \%, 2 \%$, and $11 \%$ for the MIMO1, MIMO2, and wired signal, respectively.

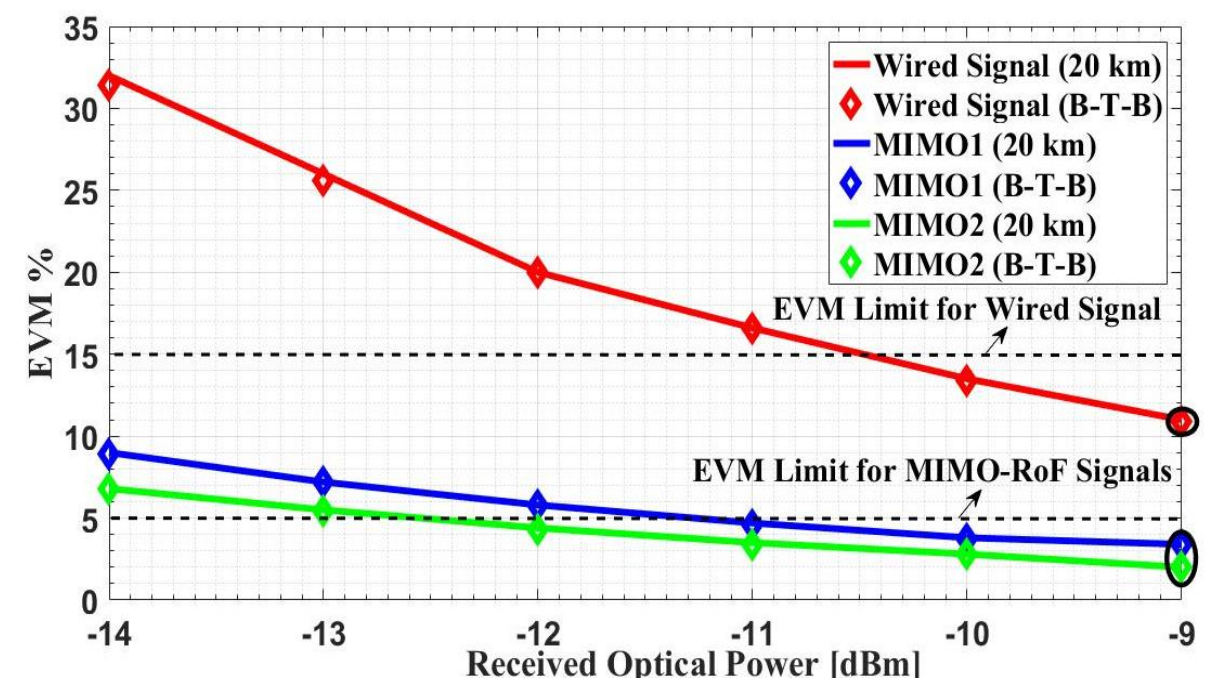

Figure 5 EVM Vs. received optical power for wired and MIMO-RoF signals with B-T-B/20 km fiber transmission

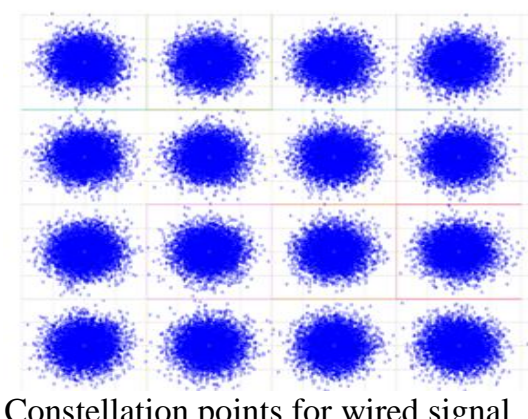

Constellation points for wired signal $\mathrm{EVM}=11 \%$

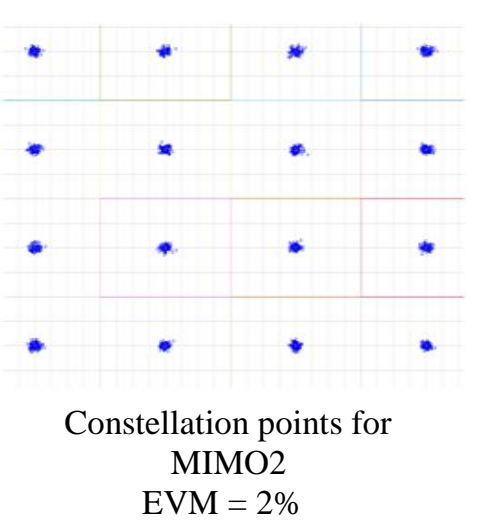

Figure 6 Constellation Diagram at -9 dBm Received Optical Power After 20 km Transmission

Moreover, since robust performance of the wireless service is highly essential, it is important to investigate the interference due to the intermixing between wired-OFDM-PON and the two MIMO-RoF in the proposed architecture. Figure 7 shows the BER versus received optical power relating to the two MIMO-RoF that was implemented in the proposed converged architecture with OFDM-PON and compare it with the non-converged system. The two MIMO-RoF in non- 
converged system was designed as in Figure 3 except that the wired OFDM-PON with 1:16 split ratio was not considered. Thus, Figure 7 shows the performance in B-T-B cases and over $20 \mathrm{~km}$ of fiber. The received optical power was considered below $-15 \mathrm{dBm}$ where BER could be reliably calculated. At the targeted BER of $10^{-3}$, the receiver sensitivities of MIMO1 and MIMO2 for non-converged system are around $-20.4 \mathrm{dBm}$ and $-21.6 \mathrm{dBm}$, respectively. However, for the converged system, the receiver sensitivities are dropped to $-15.6 \mathrm{dBm}$ and $-16.8 \mathrm{dBm}$ for MIMO1 and MIMO2, respectively. A power penalty of $4.8 \mathrm{~dB}$ is noticed for both MIMO1 and MIMO 2 in the converged system. This is due to the intermixing with wired OFDM-PON signal which leads to distortion (Wang et al., 2016) and the insertion loss accounted for 1:16 splitting ratio that degrades the system performance.

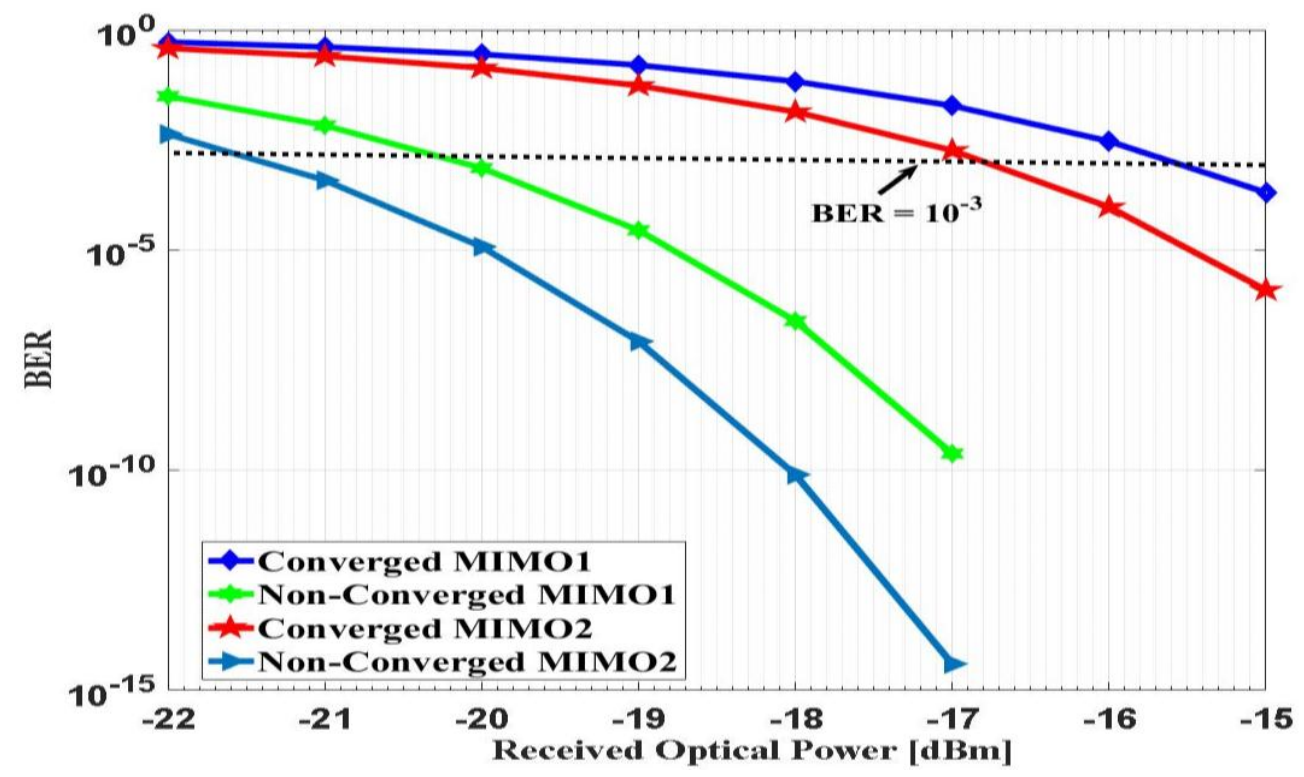

Figure 7 BER Vs. received optical power for MIMO1 and MIMO2 with converged and non-converged system over $20 \mathrm{Km}$ fiber transmission

\section{CONCLUSION}

A FiWi network including an OFDM-PON and two MIMO-RoF systems using the SSB-FT technique has been demonstrated. The main advantage of the proposed architecture is to reduce the complexity of transceiver design of both the OFDM-PON and RoF systems by applying a novel method for the implementation of LOs in both the transmitter and receiver compared to previously reported network architectures that require a LO for each of the ONUs/BSs. In addition, only one LO was employed for both the two MIMO-RoF systems and OFDM-PON. Furthermore, both the RoF systems and OFDM-PON utilized the same carrier frequency to achieve a high spectrally efficient FiWi system. The network performance was evaluated based on EVM and BER measurements. The simulated results show that the OFDM-PON and the two MIMO-RoF system has achieved the EVM target with clear constellation points. In addition, the proposed FiWi converged system was compared with non-converged system that included only the two MIMO-RoF channels. The BER performance shows that a power penalty of $4.8 \mathrm{~dB}$ due to the interference from wired-OFDM to the two MIMO-RoF channels in a converged system and insertion loss of PON splitting ratio. The simulation results verify that our scheme could be a promising candidate for converged wired and wireless networks. 


\section{ACKNOWLEDGEMENT}

This work was funded by TM R\&D Research Grant under Grant No RDTC/160914.

\section{REFERENCES}

Cano, I.N., Escayola, X., Schindler, P.C., Santos, M.C., Polo, V., Leuthold, J., Tomkos, J., Prat, J., 2015. Experimental Demonstration of a Statistical OFDM-PON with Multiband ONUs and Elastic Bandwidth Allocation. Journal of Optical Communications and Networking, Volume 7(1), pp. A73-A79

Da Silva, R., Cunha, M., da Costa, I., Cerqueira, S.A., 2017. GPON-based Front-end Architecture for 5G Networks. In: Paper presented at the Microwave and Optoelectronics Conference (IMOC)

Dahawi, T.H., Yusoff, Z., Senior, J.M., 2018. OFDM Transmission in a Converged $60 \mathrm{GHz}$ MMW RoF over OFDM-PON. In: Paper presented at the $7^{\text {th }}$ IEEE International Conference on Photonics, Malaysia

Elmagzoub, M., Mohammad, A.B., Shaddad, R.Q., Al-Gailani, S.A., 2016. Polarization Multiplexing of Two MIMO RoF Signals and One Baseband Signal Over a Single Wavelength. Optics \& Laser Technology, Volume 76, pp. 70-78

Gutiérrez, J., Maletic, N., Camps-Mur, D., García, E., Berberana, I., Anastasopoulos, M., Tzanakaki, A., Kalokidou, V., Flegkas, P., Syrivelis, D., Korakis, T., Legg, P., Markovic, D., Lyberopuolos, G., Bartelt, J., Chaudhary, J.K., Grieger, M., Vucic, N., Zou, J., Grass, E., 2016. 5G-XHaul: A Converged Optical and Wireless Solution for 5G Transport Networks. Transactions on Emerging Telecommunications Technologies, Volume 27(9), pp. $1187-1195$

IEEE Std., 2006. IEEE Standard for Local and Metropolitan Area Networks Part 16: Air Interface for Fixed and Mobile Broadband Wireless Access Systems Amendment 2: Physical and Medium Access Control Layers for Combined Fixed and Mobile Operation in Licensed Bands and Corrigendum 1, IEEE Std 802.16e-2005 and IEEE Std 802.162004/Cor 1-2005 (Amendment and Corrigendum to IEEE Std 802.16-2004) (p. 822)

Jarrar, M., Maamoun, K., Mouftah, H.T., 2015. An Enhancement to the Novel RoF-PON as a Fibre-wireless Services Enabling Technology. In: Paper presented at the Performance Evaluation of Computer and Telecommunication Systems (SPECTS), International Symposium on Performance Evaluation of Computer and Telecommunication Systems (SPECTS), pp. 1-6

Jia, Z., Yu, J., Ellinas, G., Chang, G.-K., 2007. Key Enabling Technologies for Optical-wireless Networks: Optical Millimeter-wave Generation, Wavelength Reuse, and Architecture. Journal of Lightwave Technology, Volume 25(11), pp. 3452-3471

Kani, J.-i., Terada, J., Suzuki, K.-I., Otaka, A., 2017. Solutions for Future Mobile Fronthaul and Access-network Convergence. Journal of Lightwave Technology, Volume 35(3), pp. 527 534

Kanonakis, K., Tomkos, I., Krimmel, H.-G., Schaich, F., Lange, C., Weis, E., Leuthold, J., Winter, M., Romero, S., Kourtessis, P., Milosavljevic, M., Cano, I.V., Prat, O., 2012. An OFDMA-based Optical Access Network Architecture Axhibiting Ultra-high Capacity and Wireline-wireless Convergence. IEEE Communications Magazine, Volume 50(8), pp. 7178

Latunde, A.T., Milosavljevic, M., Kourtessis, P., Senior, J., 2016. OQAM-OFDM RoF with IMDD Remote Heterodyne $28 \mathrm{GHz}$ Upconversion for 5G Millimeter RANs. In: $18^{\text {th }}$ International Conference on Transparent Optical Networks (ICTON), Trento, 2016, pp. 14 
Lim, C., Tian, Y., Ranaweera, C., Nirmalathas, A., Wong, E., Lee, K.-L., 2018. Evolution of Radio-over-Fiber Technology. Journal of Lightwave Technology, Volume 37(6), pp. 16471656

Lin, B., Li, J., Yang, H., Wan, Y., He, Y., Chen, Z., 2012. Comparison of DSB and SSB Transmission for OFDM-PON. Journal of Optical Communications and Networking, Volume 4(11), pp. B94-B100

Liu, C.-P., Seeds, A.J., 2010. Transmission of Wireless MIMO-Type Signals Over a Single Optical Fiber Without WDM. IEEE Transactions on Microwave Theory and Techniques, Volume 58(11), pp. 3094-3102

Liu, X., Effenberger, F., 2017. Evolution of Mobile Fronthaul towards 5G Wireless and Its Impact on Time-sensitive Optical Networking. In: Paper presented at the Optical Fiber Communication Conference, Los Angeles, California

Mitchell, J.E., 2014. Integrated Wireless Backhaul Over Optical Access Networks. Journal of Lightwave Technology, Volume 32(20), pp. 3373-3382

Osseiran, A., 2014. Mobile and Wireless Communications System for 2020 and Beyond (5G). In: ITU-R 2020 Vision Workshop

Oliveira, R.S., Silva, E.F., Costa, U.W., Ferreira, R., Shahpari, A., Costa, J.C., Teixeira, A.J., 2017. Coexistence of TWDM-PON and Multi RF/IF Over Fiber System: Experimental Demonstration. In: Paper presented at the Transparent Optical Networks (ICTON), 2017 $19^{\text {th }}$ International Conference on Transparent Optical Networks (ICTON), pp. 1-4

Senior, J.M., Kourtesis, P., Milosavljevic, M., Lim, W., 2012. OFDMA-PON for Future Generation Metro-access Networks. In: Paper presented at the Photonics Global Conference (PGC)

Suryanegara, M., 2016. 5G as Disruptive Innovation: Standard and Regulatory Challenges at a Country Level. International Journal of Technology, Volume 7(4), pp. 635-642

Suryanegara, M., Asvial, M., 2018. The Patterns of Innovation Agendas on 5G Mobile Technology. International Journal of Technology, Volume 9(5), pp. 876-887

Tornatore, M., Chang, G.-K., Ellinas, G., 2017. Fiber-Wireless Convergence in Next-Generation Communication Networks: Systems, Architectures, and Management. Berlin: Spinger

Tzanakaki, A., Anastasopoulos, M., Berberana, I., Syrivelis, D., Flegkas, P., Korakis, T., Mur, D.M., Ilker, D., Guttierez, J., Grass, E., Wei, Q., Pateromichelakis, E., Vucic, N., Fehske, A., Grieger, M., Eiselt, M., Bartelt, Fettweis, G., Lyberopoulos, G., Theodoropoulou, E., Simeonidou, D., 2017. Wireless-optical Network Convergence: Enabling the 5G Architecture to Support Operational and End-user Services. IEEE Communications Magazine, Volume 55(10), pp. 184-192

Wagner, C., Eiselt, M.H., Lawin, M., Zou, S.J., Grobe, K., Olmos, J.J.V., Monroy, I.T., 2016. Impairment Analysis of WDM-PON based on Low-cost Tunable Lasers. Journal of Lightwave Technology, Volume 34(22), pp. 5300-5307

Wang, J., Liu, C., Zhang, J., Zhu, M., Xu, M., Lu, F., Cheng, L., Chang, G.-K., 2016. Nonlinear Inter-band Subcarrier Intermodulations of Multi-RAT OFDM Wireless Services in 5G Heterogeneous Mobile Fronthaul Networks. Journal of Lightwave Technology, Volume 34(17), pp. 4089-4103

Zhu, M., Zhang, L., Wang, J., Cheng, L., Liu, C., Chang, G.-K., 2013. Radio-Over-Fiber Access Architecture for Integrated Broadband Wireless Services. Journal of Lightwave Technology, Volume 31(23), pp. 3614-3620 